\title{
The Politicization of Growth Theory
}

\author{
Douglas A. Hibbs, Jr. \\ Department of Economics \\ Göteborg University \\ dhibbs@economics.gu.se
}

forthcoming in Kyklos, vol. 54, 2001, 257-278

\begin{abstract}
In this essay I review the main features of neoclassical growth theory, with an eye to seeing what it has to say about the causes of wealth and poverty among nations. I argue that outside the OECD and a comparatively small circle of other countries, neoclassical models contribute little to identifying the deeper sources of cross-national patterns in growth and productivity. I then discuss recent advances in the empirical analysis of economic performance that feature the influence of politics, policy and institutional arrangements on entrepreneurship, innovation, investment and the efficiency with which factor inputs are transformed to output.
\end{abstract}

JEL Classification: O40, O57 


\section{Introduction}

International differences in economic prosperity are simply staggering. Contemporary data show that per capita incomes in the most prosperous nations are more than thirty-fold higher than in the least prosperous. And the gap between rich and poor evidently has grown during the last century and a half. (See Pritchett (1997) and McGrattan and Schmitz (1999)). Convergence of living standards cross-nationally during recent decades has been confined largely to present members of the OECD and a comparatively small number of countries outside this charmed circle experiencing growth "miracles".

One might think that economic growth and development would have occupied a prominent, if not dominant, position in the postwar research agenda of mainstream economics. But until the late 1980s mainstream growth theory was a relatively small field that for the most part was detached from, and seemingly disinterested in, broad empirical trends in the wealth and poverty of nations. Even today the revitalized field of formal growth theory is on the whole not squarely joined to empirical questions about why some countries are persistently poor, why others are persistently rich, and why a somewhat narrower group are in the process of catching up with the world's productivity leaders -- poised to become rich themselves, maybe overtaking the countries now on top.

In this essay, which is based mainly on my kctures to first year graduate students in the economics program at Göteborg University, I review the main features of neoclassical growth theory, with an eye to seeing what it has to say about the causes of wealth and poverty among nations. I then discuss recent developments in the empirical analysis of economic performance which feature the influence of politics, policy and institutional arrangements on entrepreneurship, innovation, investment and the efficiency with which factor inputs are transformed to output.

\section{Neoclassical Economic Growth}

The modern analysis of economic growth and development begins (and, for some, ends) with the neoclassical model of Solow (1956) and Swan (1956). The basic one-sector neoclassical production function models gross output, $Q$, as a twice differentiable, homogenous of degree 1 function $F(\cdot)$ of physical capital, $K$, raw labor input, $L$, and the labor augmenting state of technology, $A$ : 


$$
Q(t)=F[K(t), A(t) L(t)]
$$

Output is strictly concave in each argument, and increasing and jointly concave in all of its arguments; $F_{K}, F_{L}>0, F_{K K}, F_{L L}<0$. We need also to impose some innocuous conditions at input extremities (Ianada conditions); $\lim _{K \rightarrow \infty} F_{K}=\lim _{L \rightarrow \infty} F_{L}=0$, $\lim _{K \rightarrow 0} F_{K}=\lim _{L \rightarrow 0} F_{L}=\infty$. Technology and labor are assumed to grow exogenously. The usual specifications are exponential: $A(t)=A(0) e^{g t}, L(t)=L(0) e^{n t}$. "Effective" labor input to production, $A(t) L(t)$, therefore grows at rate $(g+n)$.

The degree 1 homogeneity of production (constant returns to scale) allows the model to be expressed in so-called intensive form, with output per effective unit of labor driven by capital per effective unit of labor:

$$
\begin{gathered}
Q=F[K, A L]=A L \cdot F[(K / A L), 1]=A L \cdot F(k, 1) \equiv A L f(k) \\
q=f(k)
\end{gathered}
$$

where $q \equiv(Q / A L), k \equiv(K / A L)$ and I drop time subscripts here and elsewhere when the meaning is plain.

Much of what can be learned from the standard neoclassical growth model stems from the first order differential equation for growth of capital per effective worker. The stock of aggregate capital evolves according to

$$
\frac{d K}{d t} \equiv \dot{K}=I-\delta K=s F(K, A L)-\delta K
$$

where $\delta$ is a fixed rate of capital depreciation and $s$ is the constant exogenous share of output saved and invested. Dividing (3) through by $A L$ and using the fact that $\dot{K} / A L=\dot{k}+(n+g) k,{ }^{1}$ we find that capital per effective worker accumulates over time according to

\footnotetext{
${ }^{1}$ The result follows from the time derivative for $k$ :

$\frac{d(K / A L)}{d t} \equiv \dot{k}=\dot{K} /(A L)-\frac{K}{A L} \cdot \frac{\dot{L}}{L}-\frac{K}{A L} \cdot \frac{\dot{A}}{A}=\dot{K} /(A L)-(n+g) k$.
} 


$$
\frac{d k}{d t} \equiv \dot{k}=s f(k)-(n+g+\delta) k
$$

The implications of the standard neoclassical setup are so well known that one may run through them quickly. The rate of output growth per effective worker is proportional to the rate of capital accumulation per effective worker. From (2b) it follows that

$$
\frac{\dot{q}}{q}=\frac{f^{\prime}(k) k}{q} \frac{\dot{k}}{k}=\alpha_{S H} \frac{\dot{k}}{k}
$$

where $\alpha_{S H}$ is capital's share of output, if capital commands its marginal product at every instant. Output per worker holds greater practical interest, however, than output per "effective" worker. Denote output per worker, $Q / L$, as $\tilde{q}$ and capital per worker, $K / L$, as $\tilde{k}$. Since $\dot{\tilde{q}} / \tilde{q}$ is just $\dot{q} / q+g$ and analogously for $\dot{\tilde{k}} / \tilde{k}$, the former evolves as

$$
\frac{\dot{\tilde{q}}}{\tilde{q}}=\alpha_{S H} \frac{\dot{\tilde{k}}}{\tilde{k}}+\left(1-\alpha_{S H}\right) g
$$

The curvature of the production function along with the Ianada conditions insure that there is a unique steady-state level of capital intensity, $k^{*}$, at which $\dot{k}=0$ : $s f\left(k^{*}\right)=(g+n+\delta) k^{*}$. Hence at steady state, output and capital per worker grow at the rate of exogenous technological progress, independent of saving, depreciation and labor force growth rates (and anything else, including policy):

$$
\left.\frac{\dot{\tilde{q}}}{\tilde{q}}\right|_{k=k^{*}}=\left.\frac{\dot{\tilde{k}}}{\tilde{\tilde{k}}}\right|_{k=k^{*}}=g .
$$

\section{Neoclassical Steady State Income Differences}

What about the steady-state level of income per worker? To say more than $\tilde{q}^{*}=F\left(\tilde{k}^{*}, A\right)$, where $\tilde{k}$ will be some function of $A, s, n$ and $g$, we need to specify $F(\cdot)$. The workhorse neoclassical specification is Cobb-Douglas: $Q=K^{\alpha}(A L)^{1-\alpha} \quad 0<\alpha<1$, in which case output per worker is $\tilde{q}=A^{1-\alpha} \tilde{k}^{\alpha}$ and steady-state capital per worker is 
$\tilde{k}^{*}=A[s /(g+n+\delta)]^{\frac{1}{1-\alpha}}$. Hence steady-state income per worker under Cobb-Douglas production is

$$
\tilde{q}^{*}=A\left[\frac{s}{(g+n+\delta)}\right]^{\frac{\alpha}{1-\alpha}} .
$$

Taking logs and indexing for the $j$-th economy yields an equation that has served as the general foundation of much empirical work:

$$
\ln \tilde{q}_{j}^{*}(t) \equiv \ln \left(\frac{Q}{L}\right)^{*}(t)=\ln A(0)+g \cdot t+\frac{\alpha}{1-\alpha} \cdot\left[\ln s_{j}-\ln \left(n_{j}+g+\delta\right)\right] .
$$

Equation (9) implies that if production is well approximated by Cobb-Douglas and an economy is very near its steady-state level of capital formation, log output per worker depends on the exogenous state of technological progress and the difference between the log of the economy-specific saving rate and the log of the economy-specific labor force growth rate plus common rates of technological change and capital depreciation. Mankiw, Romer and Weil (1992) show that equations estimated in the form of (9) can account for as much as 60 percent of variation in log output per adult across a broad cross-section of countries. But the implied share of output going to capital is too large. Growth accounting strongly suggests that capital's share of income is about a third $(\alpha \approx 1 / 3)^{2}$; Mankiw, Romer and Weil's regression estimates of (9) implied a value around 0.6.

The same point can be illustrated from a different angle by application of (8) to contemporary data. If we assume, as empirical studies based on (9) normally do, that the state of technology is a public good more or less freely available to all, and that capital depreciation rates and parameters of production do not vary significantly from one economy to the next, then international differences in output per worker are driven by saving rate differentials relative to differentials in labor force growth rates. This is can be seen directly by using (8) to take the ratio of income per worker in "rich" and "poor" countries:

\footnotetext{
${ }^{2}$ Recall that under Cobb-Douglas production $\alpha_{S H}=(\partial Q / \partial K) \cdot K / Q=\alpha$.
} 


$$
\frac{\tilde{q}_{\text {rich }}^{*}}{\tilde{q}_{\text {poor }}^{*}}=\frac{\tilde{k}_{\text {rich }}^{* \alpha}}{\tilde{k}_{\text {poor }}^{*} \alpha}=\left[\frac{s_{\text {rich }}}{s_{\text {poor }}} \cdot \frac{\left(n_{\text {poor }}+g+\delta\right)}{\left(n_{\text {rich }}+g+\delta\right)}\right]^{\frac{\alpha}{1-\alpha}} .
$$

We can safely assume $(g+\delta)$, measured on an annual basis, lies in the range 0.05 to 0.1 and that population or labor force growth rates run as high as 0.04 per year in poor countries and as low as 0.0 in rich countries. The poor-to-rich ratio of $(n+g+\delta)$ on the right-side of (10) therefore should be no greater than 2.0. The ratio of 1989 output per worker in the most and least productive 5 percent of the 137 countries in the Summers and Heston (1991) data is just over 30. At $\alpha=1 / 3$, this implies that saving rates in rich countries would have to be around 450 times higher than in poor countries in order to account for the development gap observed in late 1980's data. But at the extremes $s_{\text {rich }} / s_{\text {poor }}$ has been calibrated to be at most about 30. For representative clusters of rich and poor countries the measured ratios are more like 4.0 to 5.0. Hence, conditioned on the standard estimate of returns to physical capital, the neoclassical model cannot plausibly account for international variations in prosperity if production is well approximated by a Cobb-Douglas function.

The stock of human capital - roughly speaking the market value of the labor force's acquired skills -- may well exceed that of physical capital, at least in developed economies. (Kendrick, 1976) And the international variations are likely to be large. Even a aude measure of human capital -- the average years of formal education of the workforce -exhibits cross-national differences on the order of 8 or 10 to 1. (Jones (1998), Appendix B.) Moreover, returns to human capital probably exceed returns to physical capital. (See, for example, Psacharopoulos (1985) and the discussion in Mankiw (1995).) Broadening the concept of capital to include the stock of productive skills embodied in raw labor, and broadening the concept of saving to include the implicit costs of skill acquisition, amends the traditional neoclassical model in a way that allows it to deliver a more plausible account of international variations in prosperity.

The returns to all capital - physical plus human - are likely to be in the vicinity or 0.6 to 0.8 , as contrasted to a physical capital share commonly calibrated to be about $1 / 3$. At $\alpha=0.7$, equation (10) implies that saving rates need only vary from rich to poor countries 
by a factor of 2.2 or so in order to generate a thirty-fold difference in average productivity. ${ }^{3}$ Mankiw, Romer and Weil (1992) show that an augmented neoclassical model that includes a broad measure of capital is able to explain statistically around three-quarters of cross-national variation in levels of prosperity. However, we are left with the question of why capital accumulation exhibits large international variation. In this sense the key issue in economic development - why some countries are so rich and others so poor -- is just off-loaded to the issue of why we observe big differences in stocks of, and investment rates in, human and physical capital.

Making saving-consumption decisions endogenous, along the lines of the optimizing program of Ramsey (1928), Cass (1965) and Koopmans (1965) does not help at all. Consider the standard set up in which identical households behave dynastically so as to maximize the present discounted value of an infinite stream of utility of consumption:

$$
U=\int_{0}^{\infty} u[\tilde{c}(t)] e^{(n-\rho) t} d t
$$

where $\tilde{c}$ is consumption per adult, $n$ is the growth rate of adult members ${ }^{4}$ and $\rho>0$ is the discount rate. $u(\tilde{c})$ is assumed to be increasing and concave in consumption and it exhibits precisely the same properties as inputs to production in (1). A convergent solution (satisfying transversality) requires that $(n-\rho)<0.5$

The household's optimization problem is constrained by an equation of motion for asset accumulation:

$$
\dot{a}(t)=w(t)+(r(t)-n) a(t)-\tilde{c}(t)
$$

where $a$ denotes assets per member, $w$ is the wage rate for a unit of labor inelastically supplied each period by each household member, and $r$ is the market rate of interest.

Maximization of (11) subject to (12) yields the familiar first-order condition (Euler equation):

\footnotetext{
${ }^{3}$ For related calculations drawn from empirical studies, see McGrattan and Schmitz (1999).

${ }^{4}$ The utility maximand therefore gives aggregate or "social" utility and maps to aggregate consumption, saving and growth. One could proceed with per person utility.

${ }^{5}$ Actually in this setup a convergent solution requires that $\rho$ exceed the rate of population growth plus the utility scaled growth rate of technological progress. See ahead.
} 


$$
r(t)=\rho-\left[\frac{\tilde{c} u^{\prime \prime}(\tilde{c})}{u^{\prime}(\tilde{c})}\right] \cdot(\dot{\tilde{c}} / \tilde{c})
$$

The term in brackets is the elasticity of marginal utility of consumption (the reciprocal of the inter-temporal elasticity of substitution). Households choose consumption per adult to equate the given market rate of interest to their rate of time preference plus the rate of decrease in marginal utility of consumption owing to growing consumption per adult. A common specification of $u(\tilde{c})$ is the constant inter-temporal elasticity of substitution (CIES) function, $u(\tilde{c})=\tilde{c}^{1-1 / \sigma} / 1-\frac{1}{\sigma}, \sigma>0, \sigma \neq 1^{6}$. The CIES specification is attractive, among other reasons, because it yields a simple, intuitively appealing first order condition for the optimal path of consumption per adult:

$$
r(t)=\rho-\left(-\frac{1}{\sigma} \dot{\tilde{c}} / \tilde{c}(t)\right)
$$

so that

$$
\dot{\tilde{c}} / \tilde{c}(t)=\sigma \cdot(r(t)-\rho)
$$

Hence, the optimal time path of consumption is determined by the gap between the real return to saving and the rate of time preference, weighted by the negative of the inter-temporal elasticity of substitution of consumption (the inverse of the negative of the elasticity of marginal utility). For a given gap between $r$ and $\rho$, the higher is the propensity to substitute inter-temporally (the larger is $\sigma$ ), the larger is the response of consumption.

In the presence of technological progress $(A)$, matters are best considered as before with variables expressed per effective worker. At steady state, $\dot{k}=0$ and the capital stock per effective worker satisfies $s f\left(k^{*}\right)=(g+n+\delta) k^{*}$; therefore $s=(n+g+\delta) k^{*} / f\left(k^{*}\right)$. Under Solow-Swan the saving rate is given exogenously; so equilibrium consumption falls

\footnotetext{
${ }^{6}$ At $\sigma=1, \tilde{u}(c)=\ln c$ by l'Hôptial's rule.
} 
out as $c^{*}=f\left(k^{*}\right)-(n+g+\delta) k^{*} \cdot{ }^{7} \quad$ Equilibrium consumption in the Ramsey-CassKoopmans program depends on parameters of utility and time preference. Market competition delivers a cost of capital equal to capital's marginal product; $r(t)+\delta=f^{\prime}(k(t))$. Since $\dot{\tilde{c}} / \tilde{c}=\dot{c} / c+g$, optimal consumption growth per effective adult is

$$
\dot{c} / c(t)=\sigma \cdot\left(f^{\prime}(k(t))-\delta-\rho-g / \sigma\right)
$$

Equation (14c) shows that at steady state, saving and consumption rates in the Ramsey-CassKoopmans model must satisfy $f^{\prime}\left(k^{*}\right)=(\rho+g / \sigma+\delta){ }^{8}$

If, as before, production is Cobb-Douglas, the ordinary differential equations for growth of capital and optimal consumption imply that the steady-state saving rate is $s^{*}=\alpha \cdot(n+g+\delta) /(\rho+g / \sigma+\delta) .{ }^{9}$ Under this typical specification of the Ramsey-CassKoopmans regime (CIES utility and Cobb-Douglas production), the productivity gap between rich and poor nations implied by (10) is ${ }^{10}$

$$
\frac{\tilde{q}_{r i c h}^{*}}{\tilde{q}_{p o o r}^{*}}=\left[\frac{\left(\rho_{\text {poor }}+g / \sigma_{\text {poor }}+\delta\right)}{\left(\rho_{\text {rich }}+g / \sigma_{\text {rich }}+\delta\right)}\right]^{\frac{\alpha}{1-\alpha}} .
$$

The optimizing approach to saving and consumption is pleasing to work through because of its simplicity and elegance. Yet endogenizing saving-consumption choices sheds no light on the deeper forces generating international differences in prosperity. The mystery of why

${ }^{7}$ Equilibrium consumption would be maximized at $f^{\prime}\left(k^{*}\right)=(n+g+\delta)$-- the so-called Golden Rule level -- but there is no reason why the exogenous rate of saving would happen to take a value that created a steady-state capital stock satisfying this condition.

${ }^{8}$ Since $f^{\prime \prime}(k)<0$ (diminishing returns), steady-state saving will be lower and optimal consumption higher than what might be achieved at the Solow-Swan Golden Rule level of the capital stock, as long as $(\rho+g / \sigma)>(n+g)$. This condition must hold in a well posed optimization problem with bounded utility of consumption (satisfying transversality).

9 Given that steady-state production is $q^{*}=f\left(k^{*}\right)=k^{* \alpha}$, that $\dot{c}=0$ requires $f^{\prime}\left(k^{*}\right)=(\delta+\rho+g / \sigma)$ and that $\dot{k}=0$ requires $s=(n+g+\delta) k^{*} / f\left(k^{*}\right)$, the solution for $s^{*}$ follows.

${ }^{10}$ As earlier, technological progress, capital depreciation and parameters of production are taken to be common across economies. 
saving differentials arise in the Solow-Swan setting are just transferred to the mystery of why rates of time preference and elasticities of inter-temporal substitution vary so much. Equation (15) implies that international variations in prosperity hinge on household consumption and saving decisions in rich countries being driven by a comparatively low propensity to discount the future and by a comparatively high willingness to exploit investment opportunities by deferring current consumption in order to enjoy greater consumption later on. Households in rich as compared to poor countries evidently have greater disposition to view the future with confidence. Neoclassical theory says nothing about such disposition. (Nor does it intend to.) This issue is joined directly, however, by political analyses of growth and development, which I discuss in section V.

\section{Neoclassical Convergence}

The capacity of neoclassical theory to account for the vast international differences in prosperity were in the previous section evaluated in terms of steady-state incomes per head. Neoclassical theory makes clear predictions, however, about the path of output in route to steady state. It can be shown ${ }^{11}$ that taking a linear approximation of the neoclassical model in the vicinity of steady state yields output per effective worker as

$$
\ln q(t+T)=e^{-\beta T} \ln q(t)+\left(1-e^{-\beta T}\right) \ln q^{*}, \quad \beta>0 .
$$

Since $\ln q(t+T) \equiv \ln \tilde{q}(t+T)-\ln A(0)-g(t+T)$, and analogously for $\ln q(t)$, equation (16a) implies that observed output per worker is

$$
\ln \tilde{q}(t+T)=C+\left(1-e^{-\beta T}\right) \cdot \ln q^{*}+e^{-\beta T} \ln \tilde{q}(t)
$$

and that cumulative growth of productivity from $t$ to $t+T$ is

$$
\ln \tilde{q}(t+T)-\ln \tilde{q}(t)=C+\left(1-e^{-\beta T}\right) \cdot\left(\ln q^{*}-\ln \tilde{q}(t)\right)
$$

where $C=\left[\left(1-e^{-\beta T}\right) \cdot(\ln A(0)+g \cdot t)+g \cdot T\right] \cdot{ }^{12} \quad$ From (16c) we see that the neoclassical model predicts that growth rates should be relatively high in economies that are relatively far

\footnotetext{
${ }^{11}$ See, for example, Barro and Sala-i-Martin (1995), chapter 2 or Durlauf and Quah (1999).

${ }^{12}$ Note that taking $T=1$ and expressing (16c) for output per effective worker (so that $C=0$ ), yields a continuous time representation of the well known discrete time partial adjustment model: $\left(\ln q_{t+1}-\ln q_{t}\right)=\lambda\left(\ln q^{*}-\ln q_{t}\right)$, with $\lambda \approx\left(1-e^{-\beta}\right)$.
} 
from their steady states. ${ }^{13}$ Output per worker approaches steady state at a rate that declines as the gap between $\ln q^{*}$ and $\ln \tilde{q}$ declines and that rises as the convergence parameter (or rate of technology transfer), $\beta$, rises. In order to say more, the functional form of neoclassical production must be specified.

As mentioned already, the empirical workhorse is Cobb-Douglas, in which case cumulative growth of output per worker for given saving and labor force growth rates in the $j$-th economy would be

$$
\ln \tilde{q}_{j}(t+T)-\ln \tilde{q}_{j}(t)=C+\left(1-e^{-\beta T}\right) \cdot\left[\left(\frac{\alpha}{1-\alpha}\right) \cdot \ln \left(\frac{s_{j}}{\left(n_{j}+g+\delta\right)}\right)-\ln \tilde{q}_{j}(t)\right]
$$

where $\beta=(1-\alpha) \cdot\left(n_{j}+g+\delta\right) .{ }^{14}$ Productivity growth over some period $t$ to $(t+T)$ therefore depends on a growth constant and a depreciation constant which are given exogenously $(g, \delta)$, on economy-specific population growth and saving rates $\left(n_{j}, s_{j}\right)$, on common parameters of production $(\alpha)$, and on the initial level of output per worker $\left(\ln \tilde{q}_{j}(t)\right)$.

Many empirical studies of international variations in growth rates are loosely based on an equation like (17). Applied to data from the 1960s on growth rates of output per worker, the traditional neoclassical setup fares poorly in large international cross-sections if homogenous saving and labor force growth rates are maintained. (In this case the product to the left of the minus sign within brackets on the right-side of (17) is just a constant.) The implication is that there is little tendency for standards of living to converge to a common international steadystate potential, $\ln q_{j}{ }^{*}$ (unconditional or absolute $\beta$-convergence). However, notwithstanding occasional assertions to the contrary, the neoclassical model makes no prediction of homogenous cross-economy saving behavior, common steady-state potentials and universal convergence. Specified with economy-specific saving and labor force growth rates, the model does tolerably well in fitting cross-national variation in postwar growth performance. (Mankiw, Romer and Weil (1992) is an influential, early demonstration.) Yet with $\alpha$ equal to the stylized physical capital share of $1 / 3$, and with $\left(n_{j}+g+\delta\right)$ equal to

\footnotetext{
${ }^{13}$ This general idea appeared in the work of economic historians before the technical demonstrations of neoclassical models. See, for example, Gershenkron (1952).

${ }^{14}$ Barro and Sala-i-Martin (1995), chapter 2 supply a proof.
} 
about 0.08 per annum, the neoclassical model with Cobb-Douglas production predicts a conditional convergence rate of over 5 percent per year. Empirically, 5 percent is much too high.

If the concept of capital is broadened, however, to include human as well as physical stocks, the conditional convergence prediction of neoclassical growth theory receives much better empirical support. As I pointed out in section III, including human capital in the story increases the international variation in implied steady-state levels of capital and output, which are the "attractors" that help drive transitional growth rate dynamics. And by raising the implied share of capital in gross income, a broader conception of saving lowers the speed at which convergence in a neoclassical setting is predicted to occur. At an income share of, say, 0.7 to 0.8 going to a broadened conception of capital, the implied rate of convergence for a human capital-augmented Cobb-Douglas production function ranges from to 1.5 to 2.5 percent a year, which conforms well to results obtained by Barro (1991, 1995), Mankiw, Romer and Weil (1992), and others.

Such results are rightly taken to supply evidence favoring the neoclassical model of growth. Yet, as noted before, we are left with the question of why saving behavior exhibits large international variation. In the Solow-Swan model saving rates are taken to be exogenous, while in the optimal consumption program of Ramsey-Cass-Koopmans saving is determined by exogenous discount rates and inter-temporal elasticities of substitution. But willingness to save today in order to consume later on must surely depend upon anticipated returns to investment. So expected growth influences saving rates or, equivalently, influences the parameters of utility and time preference that determine saving. Under even weak forms of rational expectations, reverse causation from rationally expected growth to saving decisions creates doubt about what regressions including variable saving rates reveal about the sources of economic growth in general, or the dimensions and magnitudes of convergence in particular.

More persuasive are results from the path breaking studies of Barro (1991), Barro and Sala-i-Martin (1991, 1992, 1995 chapter 11) on economic growth across sub-national economies that plausibly have very similar steady states: American states, regions of the main European economies, and Japanese prefectures. In this research convergence rates were 
estimated by regressing output growth rates on initial conditions alone, ${ }^{15}$ imposing the assumption of common saving rates (and labor force growth rates). Convergence at approximately 2 percent per annum was the typical estimate. ${ }^{16}$ Convergence is also a strong feature of the results obtained at the level of national economies by Baumol (1986), Dowrick and Nguyen (1988), Mankiw, Romer and Weil (1992), Pritchett (1997), among others, for present members of the OECD. ${ }^{17}$ These studies indicate that neoclassical mechanisms work as advertised in economies functioning within a political- institutional environment of the sort enjoyed by today's rich countries. ${ }^{18}$

By comparison to much of the rest of the world, however, OECD countries and their constituent administrative units are lands of unfettered market capitalism. Nonetheless, even within the OECD community the consequences of intrusions by politics, policy, and institutional arrangements on the presumptively efficient functioning of frictionless, impersonal market mechanisms are vigorously debated. ${ }^{19}$ But relative to the great damage done to growth and standards of living by policies and institutional practices existing in many parts of the world, these debates amount to hairsplitting. Outside the circle of nations with comparatively benign, market supporting institutional frameworks, unvarnished neoclassical models contribute little to understanding the sources of growth and productivity.

\section{Political Sources of Growth and Development}

The neoclassical ingredients for modeling growth and development are the scale of factor inputs - raw labor, human capital and physical capital - the saving-investment rates

\footnotetext{
${ }^{15}$ Related regression experiments included controls for aggregate shocks and other structural variables most likely unrelated to saving behavior and exogenous with respect to growth.

${ }^{16}$ However, for reservations about the robustness of conditional estimates of convergence parameters see Durlauf and Quah (1999).

${ }^{17}$ Dowrick and Nguyen, however, interpret the negative effect of initia 1 condition output on growth to represent the speed of technological diffusion across countries, rather than the degree of decreasing returns to reproducible factors. In such regressions one cannot distinguish the two forces, which may well be jointly at work.

${ }^{18}$ Reverse causation issues arise also here, though perhaps in weaker form than with respect to connections among institutional conditions and productivity levels. (See the remarks in section V.) Yet the natural experiments supplied by the historical experiences of North and South Korea, Mao's China and Hong Kong, communist East and capitalist West Germany, or Eastern Europe altogether during and after the breakup of the Soviet bloc system, leave little doubt that politicalinstitutional conditions exert strong effects on national economic performance.

${ }^{19}$ Agell, Lundh and Ohlsson (1997) supplies an excellent review and fresh empirical results focusing on the effects on growth of the scale of fiscal activity.
} 
determining the speed at which capital accumulates to steady state, the efficiency with which factor inputs produce output (parameters of production), and the initial endowment of technological knowledge and its rate of growth. If the traditional model is re-specified to incorporate human capital, and if exogenous saving rates are permitted to vary freely across economies, the evidence cited previously shows that neoclassical equations are able to account statistically for a substantial part of the variation in average levels of productivity and are reasonably successful in tracking variation in average rates of growth. Successful economies are those with high rates of saving and investment in plant, equipment, training and education. Yet, as already emphasized, this conclusion shifts the central question of why some nations are rich and others poor to the puzzle of why saving and investment behavior varies so much.

Endogenous growth theory addresses this issue by explicitly modeling investment decisions and the process of capital formation. ${ }^{20}$ Endogenous growth models typically predict permanent growth rate responses to changes in investment, research and development and various policy variables affecting accumulation of human and physical capital. However, growth rates do not seem to be permanently affected by increased research and development and exhibit little or no persistence. (See, for example, Jones (1995a, 1995b).) Moreover as Mancur Olson (1996) pointed out, neither endogenous growth theory nor neoclassical growth theory are able to account for the stylized fact that the highest rates of growth rate tend to occur in a subset of low income countries, rather than low income countries in general as implied by neoclassical transitional dynamics, or in high income countries with well developed research and development sectors and high levels of education and training, as claimed by most endogenous growth models. The initial excitement about endogenous growth theory has largely dissipated in the light of its failure to overcome the empirical deficiencies of neoclassical theory.

Empirical research on growth and development has responded to the shortcomings of received theory by first building upon, and more recently by discarding almost completely, the standard modeling architecture. The first breakthroughs in understanding observed patterns of growth and development came via the "politicization" of neoclassical models. Politicized neoclassical growth theory emphasizes that the stocks of labor and capital

\footnotetext{
${ }^{20}$ The best overview of endogenous growth theory is Aghion and Howitt (1997).
} 
available for production, as well as the efficiency with which factor inputs are transformed to output, depend decisively on how politics, policy and institutional arrangements affect the security of property and private returns to entrepreneurship, innovation, investment and hard work. Saving behavior, and rates of time preference and intertemporal substitution of consumption - the prime movers in neoclassical models - are viewed as intermediate variables driving growth and development which themselves are determined by the political and institutional environment.

The principal contribution of politicized growth theory, however, is methodological. The main substantive message appeared long ago in North and Thomas's (1973) seminal historical analysis of the critical role played by the institutionalization of private property rights to the emergence of prosperity in the West. (See also North $(1981,1990)$ ). The novelty of the research undertaken during the last decade lies in the application of routine econometric methods to large international data sets containing improved measures of output and systematic, albeit crude, calibrations of political-institutional conditions. A flood of recent of empirical research has investigated the statistical response of growth and development to a great number of unconventional sociopolitical, policy and institutional variables. $^{21}$ By my reading of the literature, the most robust "outside" determinants of growth and development are the political-institutional indicators reported in the International Country Risk Guide (ICRG), prepared for fee-paying clients by Political Risk Services of Syracuse, New York. ${ }^{22}$

The ICRG variables consist of subjective scores on five aspects of politics, policy and institutions relevant to the security of property rights in various countries and periods: (i) the political autonomy and expertise of the public bureaucracy, (ii) the degree to which the 'rule of law' is institutionalized, (iii) the extent of government corruption, (iv) the risk of

\footnotetext{
${ }^{21}$ If 'politicized' growth regressions are conditioned on the investment rate, as in Levine and Renelt (1992), few outside variables register significant effects . This is to be expected, however, since much of the influence of politics, policy and institutions operates through investment behavior. In fact, many of the econometric studies mentioned in this essay investigated the response of investment to the same variables included in growth equations, and typically obtained parallel results.

${ }^{22}$ Durlauf and Quah (1999), Table 2 provide a concise summary of dozens of papers that include 36 different categories of test variables. Sala-i-Martin (1997) took matters quite a few steps further by running himself nearly two million regressions to test the robustness of effects of combinations of 62 test variables. He found, as did many other studies discussed later in the main text, strong growth effects from the ICRG variables; in particular the 'rule of law' variable listed below.
} 
expropriation or nationalization of property and (v) the risk of government repudiation of contracts. Several strategies have been employed to investigate the effects of these and many other measures of political and institutional conditions on growth and development.

One approach, taken for example by Olson, Sarna and Swamy (2000), applies growth accounting to the traditional neoclassical model in order to identify country-specific determinants of the "Solow residual" (total factor productivity). ${ }^{23}$ Differentiating the neoclassical production function in (1) with respect to time for $j$-th economy, and then dividing through by $Q$ to find the growth rate of output, yields the accounting equation

$$
\frac{\dot{Q}}{Q}(j t)=\alpha_{K}(j t) \frac{\dot{K}}{K}(j t)+\alpha_{L}(j t) \frac{\dot{L}}{L}(j t)+R(j t)
$$

where $\alpha_{K}=F_{K} K / Q, \alpha_{L}=F_{L} L / Q$ and $R=\frac{F_{A} A}{Q} \cdot \frac{\dot{A}}{A}$. Olson et. al. implicitly adopt the common (and I think highly unrealistic) assumption that the elasticities $\alpha_{K}$ and $\alpha_{L}$ are constant over $j$ and $t$. They assumed also that the total factor productivity residual can be partitioned into country-specific productivity effects, $R(j)$ and random shocks, $r(j t)$, with the former supplying the main channel by which politics, policy and institutions affect economic growth. The country-specific component of the growth accounting residual was obtained from a first-stage estimation of a discrete time representation of (18) for a pooled cross-section of time series covering 68 counties over the period 1960-87. The first firststage regression equation is

$$
\ln \left(Q_{j t} / Q_{j t-1}\right)=R_{j}+\alpha_{K} \ln \left(K_{j t} / K_{j t-1}\right)+\alpha_{L} \ln \left(L_{j t} / L_{j t-1}\right)+r_{j t} .
$$

In this approach, fixed country effects derived from an equation like (19) are then analyzed in second-stage regressions of the form

$$
R_{j}=a+X_{j} b+e_{j}
$$

where $X$ denotes variables for politicalinstitutional conditions and other controls, which in the Olson, Sarna and Swamy study included initial condition per capita income.

\footnotetext{
${ }^{23}$ The term 'total factor productivity' is firmly lodged in the jargon of economics, but as Abramovtiz (1956) famously observed, the growth accounting residual is more accurately (and less pretentiously) viewed as "a measure of our ignorance."
} 
Regression experiments based on (20) produced strong statistical evidence that the ICRG measures of institutional quality exert large effects on international variations in countryspecific total factor productivity. For example, Olson et. al. estimated that a composite "quality of governance" measure constructed from the five constituent ICRG variables had a growth effect of 0.27 . The composite ICRG variable ranged internationally from 1.7 (Haiti) to 9.8 (Hong Kong). The implication is that this crude measure of the quality of the political environment can account for international differences in growth rates of as much as 2.2 percent per year. The growth effects of politics and institutions estimated by Olson, Sarna and Swamy are therefore substantial. Nonetheless, they are almost certainly understated, and perhaps by a large margin.

In the growth accounting approach, the stock and flow of factor inputs are determined exogenously and parameters of production are asumed constant over all countries and periods. Yet if policy, politics and institutions affect directly the process of capital formation, the quality of labor inputs and the efficiency with which given factor inputs are transformed into value added, then the two-stage, growth accounting method of analysis will miss important channels of political influence on growth performance. The record of the command economies of the former Soviet Union and its East European clients provides an obvious illustration. The Soviet-bloc economies were distinguished by relatively high labor force participation rates, high levels of education, and high rates of (forced) saving and investment, which produced seemingly impressive stocks of physical capital. Yet these ample human and physical resources were deployed inefficiently and living standards stagnated. The reason of course is that command economies lack a system of relative market prices to guide the allocation of factor inputs, and offer few private returns to productive work effort and efficient management practice. Clearly parameters of production and associated marginal productivities cannot sensibly be held fixed across economies burdened with institutional arrangements that create large gaps between factor productivities and factor rewards.

Moreover, saving flows and accumulated asset stocks may be inefficiently transformed to additional output because of deficient demarcation and protection of property rights. As Hernando de Soto (2000) forcefully points out, accumulated capital will be incompletely utilized, or not utilized at all, if rights of ownership are not clearly established and impartially 
enforced. The problem in much of the third world, according to de Soto, is not a shortage of accumulated saving; rather it is that a great share of assets is illiquid and static. Property is inadequately documented and hence lacks a status freeing it to produce additional value. Because property is insufficiently "paperized" by enforceable legal representations, it cannot be used as a share against investment or as collateral for loans that can raise the stock of working capital. The "transformation potential" of stagnant assets to active capital depends critically on the institutional status of rights to property. The effects of the institutional environment on growth and development therefore cannot be accurately assessed by taking factor inputs as given, or by assuming that the effectiveness with which potential factor inputs are transformed to output is unaffected by the institutional conditions.

The methodological problems with research based on growth accounting are largely overcome by a more widely used approach popularized by Robert Barro's influential 1991 article in the Quarterly Journal of Economics (Barro (1991)). Research undertaken using Barro's basic setup essentially operates with a discrete time representation of (16c) to estimate determinates of potential steady-state output per effective worker, $\ln q_{j}^{*}$. The equations behind this line of research are

$$
\begin{gathered}
\ln \tilde{q}_{j t+T}-\ln \tilde{q}_{j t}=C^{\prime}-\lambda \ln \tilde{q}_{j t}+\lambda \ln q_{j}^{*} \\
\ln q_{j(t)}^{*}=a+X_{j(t)} b
\end{gathered}
$$

which yields an estimating equation for growth of output per worker

$$
\ln \tilde{q}_{j t+T}-\ln \tilde{q}_{j t}=c-\lambda \ln \tilde{q}_{j t}+\lambda \cdot X_{j(t)} b
$$

where $C^{\prime}=[\lambda \cdot(\ln A(0)+g \cdot t)+g \cdot T], \quad c=\left(C^{\prime}+\lambda a\right), \quad X_{j(t)}$ is a vector of variables determining variation in potential steady-state output (capital), and parentheses around the time subscripts indicate differences across studies about whether $\ln q^{*}$ was modeled as varying over time as well as countries. ${ }^{24}$ Notice that this test equation, which is the basic empirical setup used in dozens of studies, is unconstrained as to its arguments and relationships among its parameters. The only vestige of formal neoclassical theory is the

\footnotetext{
${ }^{24}$ Although the dependent variable in (21c) is cumulative growth of productivity, many studies use average growth rates observed across countries over one or more time ranges. In this case coefficients are just divided by $T$, the length of the accumulation period.
} 
free-form coefficient $\lambda$ on the initial condition level of output per worker, which should have a negative sign under the theoretical prediction of decreasing returns to reproducible factors. $^{25}$

Barro's initial research used calibrations of political violence and simple coding of "socialism" to measure the sociopolitical and institutional conditions that might affect the potential steady-state levels of capital and output driving transitional growth rates. ${ }^{26}$ After the appearance of important papers by Knack and Keefer (1995) and Knack (1996), however, Barro and others adopted the ICRG measures. (See, for example, Barro (1997).) Knack and Keefer's research showed that the ICRG indicators of political-institutional conditions do a better job of explaining international variations in growth than alternative calibrations. Their results, based on average growth in GDP per capita during 1974-1989 in 98 countries, implied that a shift from one extreme to the other in the average of all five ICRG indicators produces a corresponding shift of 4 percent per annum in the average rate of economic growth. This result is substantially higher than the 2.2 percent per annum upper limit effect obtained by Olson, Sarna and Swamy (2000), which is consistent with my earlier remarks about the likelihood of the growth accounting approach understating the magnitude of institutional effects on economic performance. Many other studies have reinforced the results first reported by Knack and Keefer for output growth. ${ }^{27}$. Moreover, the main message of this research applies with equal, or even greater, force to levels of prosperity.

The most recent research on political sources of economic performance has shifted from the study of growth rates to analysis of productivity levels. One important reason is that in the neoclassical empirical framework popularized by Barro (1991), differences in growth rates are transitory. If the determinants of steady-state income (capital) are stable, the dynamics of the model eventually drive all countries to converge to their own steady-state levels of income. Growth of incomes everywhere then reverts to the same exogenously given

\footnotetext{
${ }^{25}$ An alternative, though not exclusive, interpretation is that economies with low initial condition levels are able to catch-up with the technology leaders by adopting at low cost best practice technologies developed elsewhere. See Abramovitz (1986).

${ }^{26}$ However, it is likely that political violence and instability and economic growth and development are jointly endogenous. (The same is of course true of other political variables.) Hibbs (1973) undertook perhaps the first econometric analysis of the potential two-way causation between economic performance and mass political violence, with primary emphasis placed on determinants of international variations in the later.

${ }^{27}$ For example, Rodrik (1997), Sachs and Warner (1997) and, as already noted, Sala-i-Martin (1997).
} 
rate of technological progress. In fact, growth rates exhibit little persistence within countries over time, so cross-national differences are most likely quite transitory. International variation in levels of prosperity therefore supply a more secure empirical base from which to identify the impact of policies and institutions on economic performance. And income levels register directly international differences in living standards. ${ }^{28}$

Two leading examples of the recent focus on political models of output levels per head are Hall and Jones (1999) and Acemoglu, Johnson and Robinson (2000). These and similar papers posit reduced form equations representing the straightforward idea that politics, policy and institutions are what determine the scale of factor inputs and their efficiency in producing value added. Illustrated schematically the model entertained is simply:

Politics, Policies, Institutions $\Rightarrow$ Factor Inputs, Marginal Productivities $\Rightarrow$ Output

The regression equation fit to data on a large cross-section of countries in the Hall and Jones and Acemoglu et al. studies is therefore

$$
\ln (Q / L)_{j}=\alpha+\beta P I_{j}+Z_{j} \gamma+\varepsilon_{J}
$$

where $(Q / L)$ denotes output per worker or per person, $P I$ denotes politics, policies and institutions and $Z$ is a vector of additional control variables. Equation (22) represents quite a transformation of thinking in the economics profession about the sources of wealth and poverty among nations. It bears no traces at all of received theories of growth, and it is indistinguishable from the loosely motivated regression equations long populating sociology

${ }^{28}$ Regression models in the form of $(21 \mathrm{c})$ of course can be solved for the implicit time path of
productivity levels, either by simulation or, if the driving variables are stable, by direct computation.
For convenience, take $T=1$ and evaluate (21c) from period $t=0$ forward. If $X_{j(t)}$ are fixed at some
stable value, $\quad$ say $\quad \bar{X}_{j}, \quad$ the solution for $\ln \tilde{q}_{j t+1}$ would be:
$\ln \tilde{q}_{j t+1}=(1-\lambda)^{t} \ln \tilde{q}_{0}+\left[1-(1-\lambda)^{t}\right] \cdot\left(c^{*}+\bar{X}_{j} b\right)+\lambda \cdot g \sum_{j=0}^{t-1}(1-\lambda)^{j} t-j$, where $c^{*}=\left(a+\ln A_{0}+g / \lambda\right)$. The last term in the equation represents the accumulated effect on $\log$ productivity of the trend growth of technological progress. 
and political science -- disciplines that historically were not tied to a tight theoretical system analogous to the reigning neoclassical paradigm of academic economics. ${ }^{29}$

Attention is centered on the effects of policies and institutions, that is on estimates of $\beta$. Hall and Jones measure PI (they call it Social Infrastructure) with the average of the five $I C R G$ indicators described previously plus Sachs and Warner's (1995) index of the openness of countries to free trade. Their results imply that PI accounts for more than seventy percent of the thirty-five fold factor of variation in output per worker observed across 127 countries. The PI variable used by Acemoglu et al. is just the ICRG indicator of expropriation risk. They find that the expropriation risk variable by itself can account statistically for around half of the difference in income per capita across countries. It has not gone unrecognized that political and institutional arrangements do not appear randomly, but have their own historical origins. ${ }^{30}$ Drawing on historical scholarship, Acemoglu, Johnson and Robinson, for example, present an extended analysis of the colonial origins of present day institutions.

As in the case of saving rates and economic growth, reverse causation is an important problem in estimation of political models of productivity, if only because rich countries have the resources to build institutions of high quality. ${ }^{31}$ Researchers have struggled with the problem of simultaneity bias, and various instrumental variables estimators have been devised to obtain consistent estimates of the proximate effects of politics and institutions on economic performance. Although I find none of the instrumental variables approaches proposed thus far to be entirely persuasive, the evidence nonetheless strongly suggests that

\footnotetext{
${ }^{29}$ Ironically, as research by economists on growth and development and other topics has begun to discard formal theory in favor of a more institutionally grounded, empirical approach, political science has moved in the direction of traditional economics, with a growing fraction of research lodged in the a-institutional constrained optimization paradigm of microeconomic theory.

${ }^{30}$ Olson and Hibbs (2000) develop a model in which biogeographic conditions existing at the time of the Neolithic transition about eleven thousand years ago affect present day prosperity, as well as its more proximate institutional determinants.

31 The related idea that a relatively high level of economic development (and perhaps also distributions of wealth and income that are not too inequitable) are prerequis ites for democratic political development (conceived in terms of competitive politics, the rule of law, security of property rights and individual liberties, and so forth) can be traced back in the modern social science literature at least to Lipset (1959). Lipset (1981, chapter 14) comments on the more systematic quantitative investigations of the economic development-to-political-democracy thesis that were undertaken in the 1960s and early 1970s by Cutright, Olsen, McCrone and Cnudde, Winham, Diamond, among other political sociologists and political scientists. Here, as in other lines of recent research on connections among politics and institutions and economic growth and development, economists are beginning to replicate and extend the earlier work of political sociologists and political scientists.
} 
productivity and growth are to a large extent explained by politics, policy and institutions, rather than by economically endogenous processes of capital formation, or by exogenous variation in saving behavior and associated parameters of time preference and utility. Indeed, it is remarkable how potent the effects of political conditions on economic performance appear to be despite the rudimentary status of measurement. Understanding of the sources of wealth and poverty among nations would surely be advanced significantly if 'political institutional accounting' received anything like the resources devoted to national economic accounting.

\section{References}

Abramovitz, Moses (1956). Resource and Output Trends in the United States Since 1870, American Economic Review. 46 (May): 5-23.

Abramovitz, Moses (1986). Catching Up, Forging Ahead and Falling Behind, in M. Abramovitz, Thinking About Growth and Other Essays on Economic Growth and Welfare. Cambridge, England: Cambridge University Press.

Acemoglu, Daron, Simon Johnson and James A. Robinson (2000). The Colonial Origins of Comparative Development: An Empirical Investigation. Unpublished Working Paper.

Agell, Jonas, Thomas Lundh and Henry Ohlsson (1997). Growth and the Public Sector: A Critical Review Essay, European Journal of Political Economy. 13: 33-52.

Aghion, Philippe and Peter Howitt (1997). Endogenous Growth Theory. Cambridge, MA: MIT Press.

Barro, Robert (1991). Economic Growth in a Cross-Section of Countries, Quarterly Journal of Economics. 106: 407-443.

Barro, Robert (1997). Determinants of Economic Growth: A Cross-Country Empirical Study. Cambridge, MA: MIT Press.

Barro, Robert and Xavier Sala-i-Martin (1991). Convergence Across States and Regions, Brookings Papers on Economic Activity: 1991,1: 107182.

Barro, Robert and Xavier Sala-i-Martin (1992). Convergence, Journal of Political Economy. 100: 223-251.

Barro, Robert and Xavier Sala-i-Martin (1995). Economic Growth. New York: McGrawHill.

Baumol, William (1986). Productivity Growth, Convergence and Welfare: What the LongRun Data Show, American Economic Review. 76: 1072-1085.

Cass, David (1965). Optimum Growth in an Aggregative Model of Capital Accumulation, Review of Economic Studies. 32: 233-240. 
de Soto, Hernando (2000). The Mystery of Capital: Why Capitalism Triumphs in the West and Fails Everywhere Else, New York: Basic Books.

Dorwick, Steve and Duc Tho Nguyen (1989). OECD Comparative Economic Growth 195085: Catch-Up and Convergence, American Economic Review. 79: 1010-1030.

Durlauf, Steven N. and Danny T. Quah (1999). The New Empirics of Economic Growth, in: John B. Taylor and Michael Woodford, (eds.), Handbook of Macroeconomics, Volume 1A. Amsterdam: Elsevier.

Gershenkron, Alexander (1952). Economic Backwardness in Historical Perspective, in: Bert Hoselitz (ed.), The Progress of Underdeveloped Areas. Chicago: University of Chicago Press.

Hall, Robert E. and Charles Jones (1999). Why Do Some Countries Produce so Much More Output than Others?, Quarterly Journal of Economics. 114: 83-116.

Hibbs, Douglas A. Jr. (1973). Mass Political Violence: A Cross-National Causal Analysis. New York: John Wiley.

Jones, Charles I. (1995a). Time Series Tests of Endogenous Growth Models, Quarterly Journal of Economics. 110: 495-525.

Jones, Charles I. (1995a). (1995b). R\&D-Based Models of Economic Growth, Journal of Political Economy. 103: 759-784.

Jones, Charles I. (1998). Introduction to Economic Growth. New York: W.W. Norton.

Kendrick, John W. (1976). The Formation and Stocks of Total Capital. New York: Columbia University Press.

Knack, Stephen and Philip Keefer (1995). Institutions and Economic Performance: CrossCountry Tests Using Alternative Institutional Measures, Economics and Politics. 7: 207-227.

Knack, Stephen (1996). Institutions and Convergence Hypothesis: The Cross-National Evidence, Public Choice. 87 (Nos. 3-4): 207-228.

Koopmans, Tjalling C. (1965). On the Concept of Optimal Economic Growth, in The Econometric Approach to Development Planning. Amsterdam: North Holland.

Levine, Ross and David Renelt (1992). A Sensitivity Analysis of Cross-Country Growth Regressions, American Economic Review. 82: 942-963.

Lipset, Seymour Martin (1959) Some Social Requisites of Democracy: Economic Development and Political Legitimacy, American Political Science Review. 53: 69-105.

Lipset, Seymour Martin (1981) Political Man, Expanded and Updated Edition [chapter 14, Second Thoughts and Recent Findings]. Baltimore: Johns Hopkins University Press.

Mankiw, N. Gregory and David Romer and David N. Weil (1992). A Contribution to the Empirics of Economic Growth, Quarterly Journal of Economics. 107: 407-437.

Mankiw, N. Gregory (1995). The Growth of Nations, Brookings Papers on Economic Activity. 1995, 1: 275-310.

McGrattan, Ellen and James A. Schmitz, Jr. (1999). Explaining Cross-Country Income Differences, in: John B. Taylor and Michael Woodford, (eds.), Handbook of Macroeconomics, Volume 1A. Amsterdam: Elsevier. 
North, Douglass C. and Robert Paul Thomas (1973). The Rise of the Western World: A New Economic History, Cambridge, England: Cambridge University Press.

North, Douglass C. (1981). Structure and Change in Economic History. New York: W.W. Norton.

North, Douglass C. (1990). Institutions, Institutional Change and Economic Performance, Cambridge, England: Cambridge University Press.

Olson, Mancur (1996). Big Bills Left on the Sidewalk: Why Some Nations are Rich and Others Poor, Journal of Economic Perspectives. 10: 3-24.

Olson, Mancur, N. Sarna and A.V. Swamy (2000). Governance and Growth: A Simple Hypothesis Explaining Cross-Country Differences in Productivity Growth, Public Choice. 102 (Nos.3-4): 341-364.

Olsson, Ola and Douglas A. Hibbs, Jr. (2000). Biogeography and Long-Run Economic Development. Working Paper, Department of Economics, Göteborg University.

Pritchett, Lant (1997). Divergence, Big Time, Journal of Economic Perspectives. 11: 3-17.

Psacharopoulos, George (1985). Return to Education: A Further International Update and Implications, Journal of Human Resources. 20: 583-604.

Ramsey, Frank P. (1928). A Mathematical Theory of Saving, Economic Journal. 38: 543559.

Rodrik, Dani (1997). TFPG Controversies, Institutions and Economic Performance in East Asia, National Bureau of Economic Research Working Paper 5914.

Sachs, Jeffrey and Andrew Warner (1995). Economic Reform and the Process of Global Integration, Brookings Papers on Economic Activity. 1995,1: 1-95.

Sachs, Jeffrey and Andrew Warner (1997). Fundamental Sources of Long-Run Growth, American Economic Review. 87(May): 184-188.

Sala-i-Martin, Xavier X. (1997). I Just Ran Two Million Regressions, American Economic Review, (May) 87: 178-183.

Solow , Robert (1956). A Contribution to the Theory of Economic Growth, Quarterly Journal of Economics. 70: 65-94.

Solow, Robert (1957). Technical Change and the Aggregate Production Function, Review of Economics and Statistics. 39: 312-320.

Swan, Trevor (1956). Economic Growth and Capital Accumulation, Economic Record. 32: 334-361. 